\title{
The Consideration Of Fraud In A Financial Statement Audit: Some Study Questions
}

\author{
Eddie Metrejean, Georgia Southern University \\ Lou X. Orchard, (Email: Lou.Orchard@wichita.edu), Wichita State University \\ L. Dwight Sneathen, Jr., (Email: dsneathen@georgiasouthern.edu), Georgia Southern University
}

In October 2002, the Auditing Standards Board (ASB) issued Statement on Auditing Standards (SAS) No. 99, Consideration of Fraud in a Financial Statement Audit in response to recommendations from the Fraud Task Force. SAS No. 99 is intended to improve auditor performance during audits and to increase the likelihood that the auditors will detect fraudulent financial reporting if any is present. Since fraud awareness is such a major part of any audit, accounting students should be well versed on the content of SAS No. 99. However, not all accounting students read SASs in detail. Then how do accounting educators get this important content to these students?

One answer is to present the information in the form of questions and answers. Accounting educators can give students the questions and require the students to do research to find the answers. The students are therefore forced to look at SAS No. 99 in detail and formulate logical answers. Such an assignment helps students to develop research skills and improve their oral and written communication skills, if used appropriately.

This paper presents questions and suggested answers that are intended to help auditing students improve their understanding of how the possibility of fraud should affect a financial statement audit. Some (or even all) of these questions could be provided to students who would then be given time to research and study the auditing literature and provide their written responses or present their responses to the class. Some of these questions might be appropriate for examinations, although only cautious use as such is recommended if the exam is closed-book because some questions require thorough research of possibly several sources.

The basic source material that students will use in answering these questions is Section 316 of the AICPA Professional Standards (AU Section 316, "Consideration of Fraud in a Financial Statement Audit"), which is based on SAS No. 99. Occasionally, other auditing standards (as noted) provide information useful to students in formulating their responses, which requires the student to think about the question and related material in AU Section 316 and go beyond the material in AU section 316 to come up with their answers. In cases where at least a part of the suggested answer can be found in AU Section 316, the suggested answer includes a reference to the applicable section(s) of AU Section 316.

Below are several potential questions that can be used to further students' understanding of the consideration of fraud in a financial statement audit.

1. While preparing the audit plan for Client X, Mary, your senior manager, is considering the extent to which she can use the client's internal audit staff. She has posed the following question for you to research. How much involvement can the client's internal auditors have in assisting independent auditors in carrying out their responsibility for considering the possibility of fraud, and what specific aspects of the audit related to the possibility of fraud, if any, are they able to assist with? Please consider separately areas where there is a specific identified risk of fraud that is not mitigated by a control policy or procedure vs. areas where there is not such an unmitigated specific identified risk. You might also want to consider separately the information gathering and assessment phase vs. the performance phase of the audit.

Suggested Answer: Generally speaking, the independent auditor should not utilize the assistance of the client's internal audit staff in areas where there is a specific identified risk that is not mitigated by a control policy or procedure. That is, the independent auditor should not reduce his or her own substantive testing; the independent auditor should perform $100 \%$ of the substantive testing in areas where there is a specific 
identified risk, unless the independent auditor has identified and tested a control activity that reduces the specific identified risk.

AU Section 316 specifies how the possibility of fraud should affect the independent audit in various phases of the audit. During the information gathering and assessment phase, the independent auditor should conduct all interviews with management, evaluate the results of analytical procedures to identify fraud risk factors, decide whether identified fraud risks exist, and determine the audit plan for such risks. During this phase, the role (if any) of the client's internal auditors should be limited to gathering documents requested by the independent auditor and coordinating activities such as interviews.

In the performance phase of the audit, the independent auditor is responsible for performing audit procedures in areas identified as specific risks and evaluating such evidence. Generally speaking, audit procedures related to any identified fraud risks should therefore be performed by the independent auditor. However, it may be appropriate for internal auditors to provide assistance with procedures such as the following:

- $\quad$ Documenting the journal entry process;

- $\quad$ Performing tests of controls over certain journal entries (e.g., the routine or "standard" journal entries);

- Accumulating information necessary for the independent auditor to perform his or her retrospective evaluation of management's estimates for bias, and

- Extracting significant and unusual journal entries under the supervision of the independent auditor, including underlying supporting documentation, and providing these entries and documentation to the independent auditor for testing and evaluation.

2. While drafting a management representation letter at the end of fieldwork, a new staff member asks you whether the possibility of fraud would affect a "typical" management representation letter. How would you respond to your new staff member (Hint: also see AU Section 333, as amended by SAS 99).

Suggested Answer: (based on AU 333.06 and 333.16): An amendment to SAS No. 85, Management Representations, which was adopted concurrently with SAS 99, revised the representations regarding fraud. The SAS 85 amendment includes specific representations concerning the following:

- Management's acknowledgment of its responsibility for the design and implementation of programs and controls to prevent and detect fraud;

- $\quad$ Management's knowledge of any fraud or suspected fraud affecting the entity that involves (1) management, (2) employees who have significant roles in the client's internal control system, or (3) others where the fraud could have a material effect on the financial statements, and

- Management's knowledge of any allegations of fraud or suspected fraud affecting the entity that were received in communications from employees, former employees, analysts, regulators, short sellers, or others. (Note: management's representations with respect to fraud should not to be limited by a materiality threshold.)

3. As senior manager your new hire is struggling with the extent to which she must query management about the risk of fraud. Specifically, who would typically be included in the term "management" (e.g., for purposes of inquiries of management about the risks of fraud and for purposes of management representations about fraud)?

Suggested Answer: (based only in part on AU 333.16): "Management" would typically include the Chief Executive Officer, Chief Financial Officer, Chief Operating Officer, IT Director, and Controller, or individuals with similar positions. SAS 99 also provides that the independent auditor should inquire directly with the audit committee, appropriate internal audit personnel, and others within the entity about the existence or suspicion of fraud. 
4. To what extent should management compensation and incentives be considered when evaluating the perceived pressure on management, and why? What steps, if any, should an auditor consider taking as a result of your answer?

Suggested Answer: (based in part on AU 316.85 section A.2): SAS 99 identifies the pressures and incentives of management as one element to consider in identifying fraud risks. Thus, independent auditors must gain an understanding of management's compensation and incentive systems as part of their overall task of understanding the business to identify financial reporting risks, including fraud risks. Independent auditors should consider doing the following:

- $\quad$ Reading the entity's code of ethics to understand its policies on related-party transactions by management;

- $\quad$ Requesting a schedule from the entity identifying (1) all incentive agreements or plans, (2) the nature and extent of any related-party transactions, and (3) any other relationships with management;

- $\quad$ Requesting copies and reading agreements, letters, or promises (e.g., employment contracts, stock option/award agreements);

- $\quad$ Reviewing the prior year's proxy statement;

- Inquiring of management, in-house counsel, and the compensation committee chairperson as to:

- The existence and nature of any other related-party transactions or relationships;

- Whether there have been any code-of-ethics violations; and

- $\quad$ Reading minutes of compensation committee meetings.

5. Which members of the audit firm should be included in the engagement team's discussion of the possibility of fraud? Please consider the case of a large CPA firm conducting an audit requiring various types of expertise not required on all audits, where auditors from many offices are involved.

Suggested Answer: (based in part on AU 316.14-18): SAS 99 (paragraph 14) specifically requires the involvement of the auditor with final responsibility for the audit - typically, the partner in charge of the audit. All firm personnel assigned to the audit, other than for administrative duties, would usually be included in these discussions. Firm members who participate in very limited auditing roles, but who are involved in an area susceptible to a risk of fraud, may also need to be included in the discussion at some point. For example, firm members whose only involvement in the audit is the observation of physical inventories might be involved in the discussion during a meeting or conference call prior to the physical inventory observations or during an onsite meeting of the audit team at the physical inventory location. Other firm members, such as those providing expertise in areas such as taxes, business valuation, electronic business, and forensic auditing, should be included as applicable. When it is not practical to include all of these firm members in the initial discussion, it may be appropriate for one or more representatives from the groups mentioned above to participate in the discussion and then hold separate discussions to keep their respective teams informed.

In the case of multi-location engagements, it is important that the audit team not view this as a single discussion, but rather a process for accomplishing the goals of SAS 99 in a thoughtful and substantive manner. This process might begin with a discussion among the principal team members, followed by further discussion with other team members. Alternatively, it may begin with a discussion among audit team members who will be working at the client's location, with later discussions that include the principal team members. The key objective of this process is to ensure that engagement team members participate in a discussion and that they understand the areas that represent a fraud risk so they can apply the appropriate level of professional skepticism. Auditors may want to consider including in these discussions an in-house forensic auditing specialist or someone else with special expertise in identifying fraud risk factors.

6. How do internal controls affect the auditor's identification of fraud risks? 
Suggested Answer: (based on AU 316.02 and 316.35-42): The auditor should identify fraud risk factors and fraud risks without regard to considering the effectiveness of the client's internal controls. That is, when the auditor is identifying fraud risks, he or she should not consider the existence or effectiveness of internal controls at that stage. Internal controls are to be considered in a separate stage of the audit.

7. The AICPA has issued an Exhibit to SAS 99, Management Anti-Fraud Programs and Controls, Guidance to Help Prevent, Deter, and Detect Fraud (see the Exhibit in AU 316.86). Would it be appropriate to share this exhibit with the client? If so, which client personnel should receive it, and for what purpose?

Suggested Answer: (based in part on AU 316.86): Yes, sharing this document with appropriate client personnel would be considered an audit "best practice." The document should be shared with the client's board of directors, audit committee, internal auditors, and at least senior members of management (the astute student might surmise this from the fact that, according to the Exhibit in AU 316.86, the exhibit was jointly issued by numerous institutions that include Financial Executives International, the Institute of Management Accountants and the Institute of Internal Auditors, and the fact that it was reviewed by the National Association of Corporate Directors). One reason for sharing the document would be to help the client selfassess how their internal control system compares with the benchmark spelled out in the exhibit. Another reason would be to help any publicly-traded clients (or those with plans to become publicly traded) comply with the internal control certification requirements of Section 404 of the Sarbanes-Oxley Act of 2002.

8. When would it be appropriate to rely on internal controls to mitigate a specific fraud risk? Please consider separately controls meant to protect assets from theft or defalcation vs. controls meant to prevent fraudulent financial reporting.

Suggested Answer: (based only in small part on AU 316.43-45): Whether or not it is appropriate to rely on internal controls to mitigate a specific fraud risk depends on the type of fraud risk being mitigated (for example, misappropriation of assets vs. fraudulent financial reporting) and on the nature of the internal control used to mitigate the risk. Within the COSO (Committee of Sponsoring Organizations of the Treadway Commission) framework, controls may exist at the control environment and/or the control activities level within an organization.

Regarding controls to protect assets from theft or defalcation, an organization might have specific controls (e.g., general control activities complimented by an effective internal control environment) that are effective at mitigating the specific fraud risk. For example, a high-end electronics store might have specific controls to safeguard its inventory from theft or defalcation. If the auditor judges these controls to be effective, he or she could choose to test and rely on those controls to mitigate a specific fraud risk. However, regarding controls meant to prevent fraudulent financial reporting, it would be rare that such controls would, by themselves, be reliable enough or that the auditor would be able to test them sufficiently enough, to mitigate a specific risk of fraudulent financial reporting. On the other hand, a lack of effective internal control would generally indicate an increased risk of fraudulent financial reporting that the auditor should consider in designing the audit.

9. If revenue is presumed to be a fraud risk, should all revenue-related account balances and assertions always be considered to be specific identified risks and always be tested using a high assessed level of inherent risk and a low allowable level of detection risk (i.e., using a high level of substantive testing)? Why or why not?

Suggested Answer: (based in part on AU 316.41-67): Not necessarily. Auditors design the nature, extent, and timing of their substantive tests at the account balance and assertion level. In other words, the nature, timing, and extent of the auditor's substantive testing procedures will depend on the account in question as well as the specific assertion (existence or occurrence, rights and obligations, completeness, valuation or allocation, presentation and disclosure) being tested. Therefore, the auditor needs to consider how this risk of fraud could affect the related transactions, account balances, and assertions. He or she would design the audit response accordingly. Thus, it would be possible to have a strategy of relying on controls and an 
intermediate level of substantive testing for some transaction types or assertions for revenue, even though the auditor has identified risks of fraud related to revenue.

Example A: A publicly-traded client manufactures and sells its product using standard terms of sale and a standard selling price. The auditor may conclude that the risk of fraud related to revenue is not related to the client's systematic, routine transactions. However, he or she may conclude that there is a risk of revenuerelated fraud corresponding to: (1) the possible existence of large transactions near period end, (2) significant increases in volume to one or more customers (possible channel stuffing), (3) improper period-end cutoff, and (4) new customers. As a result, it may be appropriate for the auditor to adopt a control-reliance strategy (with, say, a moderate assessed level of control risk) for certain assertions (e.g., existence or occurrence, completeness, valuation or allocation), allowing the auditor to achieve a moderate level of allowable detection risk (i.e., a moderate level of substantive testing), supplemented by focused procedures designed to address the possibility of misstatements related to large transactions near period end, significant increases in sales volume to one or more customers, cutoff errors, and unusual transactions.

Example B: A privately held company has four different lines of business and, accordingly, four different revenue sources, each with different characteristics and terms. The auditor might conclude, based on the characteristics of the different lines of business, that two of the sources do not represent a significant risk of fraud, while the other two sources do. The auditor would therefore design the nature, timing, and extent of substantive procedures to respond to the risks identified.

10. Under what circumstances (related to, for example, industry-specific factors, type of transactions, or the control environment), if any, would it be appropriate to conclude that revenue is not a risk of fraud?

Suggested Answer: (based only in part on AU 316.41): SAS 99 does not provide any specific guidance on circumstances under which an auditor would be justified in concluding that it would be appropriate to not identify revenue as a fraud risk. In addition, the authors are not aware of any circumstances or general characteristics (such as type of transactions or industry) that would overcome the auditor's presumption that revenue recognition should be considered a risk of fraud. A strong argument can be made that it would be unusual for a publicly-traded company or for a privately-held company with performance incentives or targets, such as stock options or debt covenants, not to have a risk of fraud related to revenue recognition. Even smaller privately-held entities with no debt or not-for-profit entities might have motivations that could result in fraudulent activities regarding revenue recognition (e.g., motivations related to taxes, funding, and/or grants).

It is best to pinpoint the risk of fraud to the related transaction, account balance, or assertion and respond accordingly.

11. Recognizing that every audit, and thus every audit plan and audit program, is unique, what changes should be made to "generic" or standardized audit plans and/or audit programs as a result of SAS 99 in order to support addressing revenue recognition as a risk of fraud?

Suggested Answer: (based in part on AU 316.41-67): For every audit, the auditor should consider the following three questions:

- For this entity, is there a risk of material misstatement due to fraud relating to revenue recognition?

If the auditor answers this question "yes," then he or she should plan audit procedures related to both any understatement risks identified and to any overstatement risks identified. If the answer is "no," the auditor should document the reason that revenue recognition is not considered a risk of fraud (however, please see question 10 above). 
- $\quad$ Based on the specific circumstances of the entity being audited, should procedures in a standardized audit program be tailored or should the auditor design additional procedures to address the risk of material misstatement due to fraud relating to revenue recognition?

The purpose of this question is simply to remind auditors to tailor any standardized audit program for specific risks. As in other specific risk areas, it is the auditor's responsibility to tailor any standardized audit program for the unique facts and circumstances of the audit being conducted to adequately address the identified risk.

If the auditor answers this question "no," he or she should document which steps in the standardized audit program adequately address the nature, timing, and extent of the specific procedures intended to respond to the risk.

- Has the risk of material misstatement due to fraud related to revenue recognition been incorporated into the audit risk model?

The purpose of this question is to provide a reminder to the auditor to incorporate (five times for each relevant account, once for each assertion) the risk of material misstatement due to fraud related to revenue recognition into the determination (via the audit risk model) of the allowable level of detection risk and thus the nature, timing, and extent of substantive testing procedures. This may be done using the formula approach or the matrix (table) approach.

12. Are auditors required to test controls over journal entries?

Suggested Answer: (based on AU 319 and AU 316): No. Auditors are required to gain an understanding of internal controls over the journal entry process and to determine whether these controls have been placed in operation. However, as with any other decision about whether to adopt a control reliance strategy, auditors have the option of deciding not to rely on controls over journal entries. Paragraph 58 of SAS 99 indicates that auditors should "inquire of individuals involved in the financial reporting process about inappropriate or unusual activity relating to the processing of journal entries and other adjustments."

The extent of understanding of internal control required by generally accepted auditing standards is specified in AU 319, Consideration of Internal Control in a Financial Statement Audit.

13. What are the audit implications of a control reliance strategy for journal entries? In your answer, please consider "standard" journal entries vs. "nonstandard" ones separately.

Suggested Answer: (based on AU 319 and AU 316): A control reliance strategy may reduce the amount of assurance needed from substantive testing. It may be useful to divide journal entries into two populations for consideration: (1) standard journal entries (often considered a "normal" risk), and (2) nonstandard journal entries (often considered a specific risk).

Standard journal entries: These may consist of automatic feeds and/or manually prepared entries to record subsidiary ledger activity and routine, recurring closing entries. Auditors generally try to adopt a control reliance strategy for these entries, often by testing controls using either corroborative inquiry in conjunction with an examination of documentation, or an examination of documentation alone. A dual purpose test of examination of documentation (e.g., 25 items) might be sufficient to achieve, in conjunction with other substantive tests (e.g., key account reconciliations and analyses) the desired level of both the control and substantive assurance for standard journal entries, assuming there are no specific identified risks.

If controls are not tested for audit efficiency reasons (i.e., a full substantive approach is used), the auditor should judgmentally determine the extent of substantive testing required by considering the necessary level of assurance (from the audit risk model) and other auditing procedures performed. For example, standard 
journal entries related to the systematically processed subsidiary ledger systems may be adequately addressed by other auditing procedures (testing account reconciliations, confirmations).

If controls are found to be deficient, the auditor should consider whether a specific risk exists and respond accordingly. Otherwise, the guidance in the preceding paragraph would apply.

Nonstandard journal entries: SAS 99 identifies the possible existence of significant nonstandard entries as an area of risk in all audits. In referring to tests of journal entries, paragraph 61 of SAS 99 specifies that "even though controls might be implemented and operating effectively, the auditor's procedures for testing journal entries and other adjustments should include the identification and testing of specific items."

SAS 99 reminds the auditor to identify and select journal entries and other adjustments for testing and focusing on the identification of entries that possess the characteristics of fraudulent entries or adjustments. These characteristics are often associated with entries: (1) made to unrelated, unusual, or seldom-used accounts; (2) made by individuals who typically do not make journal entries; (3) recorded at the end of the period or as post-closing entries that have little or no explanation or description; (4) made either before or during the preparation of the financial statements and that do not have account numbers, or (5) containing round numbers or a consistent ending number. In addition to those characteristics identified in SAS 99, the auditor may want to consider entries between reserve accounts, reclassification entries between asset and liability accounts, and entries related to industry-specific accounts (e.g., vendor allowances).

Nonstandard journal entries warrant focused tests because they are a specific risk area. As a result, the auditor should test all significant nonstandard entries showing evidence of specific characteristics, such as those listed above, for the period of interest unless already specifically addressed in conjunction with other substantive tests (e.g., key account reconciliations and analyses).

14. Can the tests of journal entries for authorization/approval be done on a rotation basis (e.g., by testing journal entries related to the business cycles that the auditor is testing)?

Suggested Answer: Yes, it is conceivable, for financial statement audit purposes (but not for attest purposes under Section 404 of the Sarbanes-Oxley Act of 2002) that the standard journal entry process could be tested on either a rotation basis or using an overall approach. The approach would probably depend on a consideration of relevant factors (for example, the number of locations and application systems and the extent of variation in preparing and processing journal entries across the processes or locations).

15. What are appropriate sample selection techniques for testing journal entries? In your answer, please consider "standard" journal entries vs. "nonstandard" ones separately.

Suggested Answer: (based in part on AU 316.61): For "standard" journal entries (see question 13 above), the extent of tests and the selection of items for testing should be determined judgmentally, which neither precludes nor requires the use of statistical sampling methods.

"Nonstandard" journal entries are another matter entirely. By their nature, nonstandard journal entries tend to have distinguishing characteristics - warning signs such as those mentioned in paragraph 61 of SAS 99 and in question 13 above - that identify them as high-priority candidates for testing. It is usually more effective for the auditor to select these items for testing (based on the likelihood that they will reveal misstatements) and to evaluate the results judgmentally, than it is for the auditor to use statistical sampling techniques.

The population of nonstandard journal entries that the auditor should test includes not only those that have been posted to the general ledger, but also any "de facto" journal entries in the form of adjustments, reclassifications and/or consolidation entries made directly to the financial statements or on the consolidation worksheet but not (yet) formally reflected in the books. 
16. While conducting preliminary analytical procedures, your new hire is wondering whether she should review and consider prior year accounting estimates. Is a retrospective review appropriate? If so, how, and for what purpose?

Suggested Answer: (based in part on AU 316.63-65): Yes, the auditor should perform a retrospective review of the prior year's estimates. He or she should first ask that the entity gather and provide the information necessary to perform this review. The entity generally has the ability (either through IT systems or manual processes) to collect the information necessary to perform the review for many estimates (e.g., bad debts, impairments). However, there may be certain estimates (e.g., inventory reserves, workers compensation) for which the client may need to either implement a manual process or enhance existing IT systems. Next, the auditor should consider and test (as applicable) the accuracy and completeness of any system-generated or manually-prepared data. Finally, the auditor should compare the "actual incurred or realized" data to the estimate from the prior year and seek plausible explanations for any significant differences. The auditor would then consider the significant current year estimates in light of the results of the retrospective review and other relevant factors (e.g., current trends, fraud risks) in order to identify and conclude whether there appears to be any identifiable trend or bias that may indicate that the financial statements are misstated.

17. During the planning phase of the audit, the audit committee has inquired about what procedures will be performed regarding fraud. How much information should the auditor communicate to the audit committee regarding the auditor's specific procedures meant to address SAS 99?

Suggested Answer: It is probably a good idea for the auditor to discuss with the audit committee the impact of SAS 99 on the nature, extent, and timing of auditing procedures. The discussion might be structured around the framework of the following main audit activities:

- Information gathering - covering scope of inquiries, analytical procedures, and other sources;

- $\quad$ Risk assessment - covering the nature of the fraud risks identified;

- $\quad$ Audit response - covering the nature of the auditor's response; and

- Concluding - covering protocols for communicating to the Audit Committee.

Information relating to the details of the auditor's approach and how the auditor executes the audit plan (for example, how the auditor determines, using the audit risk model, the specific levels of substantive testing required, how the auditor establishes materiality levels, and how the auditor calculates sample sizes), especially any proprietary aspects of either, are generally not necessary for the audit committee to properly execute their fiduciary duty.

\section{SUMMARY}

These questions and suggested answers are intended to help auditing students improve their understanding of how financial statement audits are affected by the possibility of fraud. One potentially quite fruitful use of the questions is to distribute some or all of them to students (without the suggested answers), allowing plenty of time for them to consider and research how they would answer them, then ask them to come to class prepared to discuss (and possibly turn in) their responses. The questions serve as a basis for considering Section 316 of the AICPA Professional Standards (AU Section 316, "Consideration of Fraud in a Financial Statement Audit"), which is based on SAS No. 99 and its implications for auditors. CPA firms would likely be very interested in new hires who are well versed on SAS 99 and the consideration of fraud in a financial statement audit. These questions will expose the students to the important content in SAS 99, while at the same time getting accounting students used to researching professional issues. By requiring that the students submit written answers or discuss the answers in class, the accounting educator also helps the students to improve their written and oral communication skills, which are highly sought after by CPA firms. 